\title{
Heating schemes and process parameters of induction heating of aluminium sheets for hot stamping
}

\author{
Yankang Tian ${ }^{1}$, Libo Wang ${ }^{2}$, Gerald Anyasodor ${ }^{1}$, Zhenhai Xu ${ }^{1}$, and Yi Qin ${ }^{1, *}$ \\ ${ }^{1}$ Centre for Precision Manufacturing, University of Strathclyde, Glasgow, G1 1XJ, UK \\ ${ }^{2}$ School of Manufacturing Sciences and Engineering, Sichuan University, Chengdu, Sichuan, PR China
}

Received: 14 December 2018 / Accepted: 3 May 2019

\begin{abstract}
Induction heating is one of the most popular metal heating technologies due to its high heating rate and high energy efficiency. This method is suitable for heating workpieces/blanks in different shapes, sizes and materials. Although induction heating of metal sheets has already been investigated by various research organizations and industrial companies, information concerning the induction heating of aluminium blanks is limited. Considering that hot stamping of aluminium sheets for automotive and aerospace applications is currently attracting a lot of attentions, it is timely important to gain more understanding on this technology by conducting in-depth investigations. Especially, investigations are required to address issues relating to the uneven temperature distributions developed in the metal sheets when they are heated, so that optimum designs could be obtained to improve the technology and its applications. This paper presents an in-depth analysis conducted recently for the investigation into heating schemes and process parameters in induction heating of aluminium sheets, mainly using 3D FE simulations, based on a general experimental validation. Different material, coil geometric and power-setting factors were considered during the modelling and analysis to examine their effects on the heating efficiency and developed temperature profiles. It was revealed from the simulations that design features of the induction coils affect the uniformity of the developed temperatures in the metal sheets. It is shown that an optimised combination of the coil design and the power setting could help to achieve higher heating rates, at the same time, also to achieve higher temperature-distribution uniformity. At the end of this paper, a discussion of practical factors that affect applications of induction heating of aluminium sheets for hot stamping applications is presented.
\end{abstract}

Keywords: Induction heating / aluminium sheet / FE simulation / hot stamping

\section{Introduction}

In a hot stamping process, a blank is heated up to a desired forming temperature before being transferred to the press and formed into a designated shape. During the last decade, increasing demand for hot stamping of high strength material has been seen due to dramatic developments in the automotive industry. This has created new requirements for the heating process. In order to enable the hot stamping process for various applications, to-date, several metal-blanks heating technologies have been developed and used in industry.

Convection furnace heating is the most commonly used heating method due to its simplicity and ease for handling metal sheets of different materials, shapes, and sizes. Moreover, the temperature of the blank can be controlled and maintained very easily, and it is suitable

\footnotetext{
* e-mail: qin.yi@strath.ac.uk
}

for mass production. However, a convection heating process usually has a very low heating rate and requires a longer cycle time. A furnace system which needs to be warmed up before production usually has low energy efficiency. It is one of the most intensive energy consumers in a hot-stamping production line and a furnace continuously running contributes greatly to greenhouse gases [1].

Resistance heating is another popular metal-blank heating method with high heating rates, high energy efficiency [2-4], and it is cost effective. In a resistance heating process, the temperature on a workpiece is increased due to the Joule heat generated as a result of electrical resistance when the metal is electrified [4]. However, this heating method is size sensitive which means that the temperature uniformity of the workpiece depends largely on the geometry of the blanks and where the electrodes are applied [3]. It requires the blanks to have regular shapes and constant thicknesses in order to obtain an even temperature distribution for hot stamping. 
Table 1. Material properties.

\begin{tabular}{lllll}
\hline Parts & Material & $\begin{array}{l}\text { Specific heat capacity } \\
(\mathrm{J} / \mathrm{kg} \cdot \mathrm{k})\end{array}$ & Emissivity & $\begin{array}{l}\text { Electrical resistivity } \\
(\Omega \cdot \mathrm{m})\end{array}$ \\
\hline Blank & Al-alloy & 935 & 0.75 & $3.8 \mathrm{e}-05$ \\
Coil & Copper & 386 & 1 & $1.67 \mathrm{e}-05$ \\
\hline
\end{tabular}

A method based on induction heating may have a good balance between process flexibility and energy efficiency [5-7]. A wide range of materials can be heated up by the induction heating method while a fast heating rate can be achieved. Metal sheets in different shapes and sizes can be heated by induction heating. This method is energy efficient since the heat is generated from inside the workpiece. Induction heating has already been widely used for surface heat treatment in order to minimise heat treatment distortion and obtain favourable compressive residual stresses $[5,6,8]$.

Induction heating uses an alternating electromagnetic field to heat the electrically conductive materials without physical contacts $[9,10]$. The workpiece is placed within an intense alternating magnetic field which is generated by a strong current with a high alternating frequency through the induction coils. The material is heated up due to Faraday's law. Since it is a non-contact heating method, the contamination of workpiece is largely avoided. In recent years, the use of induction heating in different manufacturing processes has increased due to the high heating efficiency and good reproducibility of the process. One of the popular research topics is the use of induction heating for aluminium alloy [11-14].

Temperature distribution in the workpiece and the heating rate induced by induction heating are determined mainly by the workpiece material, coil design [15], power of the alternating current and other electrical parameters $[16,17]$. Induction heating of metal sheets has been investigated by various research institutions and industrial companies [18,19]. At the same time, numerical simulations have been used to study the induction heating processes. Most of these studies were focused on the heating of workpieces in cylindrical or tubular shapes [20-22]. Sun et al. simulated a heavy cylinder inductively heated by six coils [20]. The temperature distribution in the workpiece was improved through attaching heat treatment rings to the ends of the cylinder. Fu et al. investigated the performance of a longitudinal magnetic flux (LMF) coil and a transverse magnetic flux (TMF) coil for preparing workpieces for gear rolling [21]. Their simulations showed that the LMF coil produced an improved performance for induction heating in terms of better temperature distribution, shortened process time, and a higher heating efficiency. Lenka et al. simulated an induction heating process for heating a steel plate and a uniform temperature profile was obtained in the workpiece through adjusting the positions of the inductors [5].

Although several investigations have been conducted to study the induction heating of workpieces with different materials and geometries, information concerning the study of induction heating of Al-alloy blanks for hot stamping was limited. Also, further investigations were requested by industry to address the issues relating to the uneven temperature distributions developed in the metal sheets during induction heating as well as the heating rates achievable with reference to the certain coil designs and power inputs.

A series of numerical simulations have therefore been conducted to study the induction heating process with reference to different kinds of setups and heating parameters. In this paper, the models developed are described firstly, being followed by a presentation of the numerical results. The focus is on the factors that influence inhomogeneous temperature distributions in the blanks and possible methods for reducing the temperature differences. The initial experimental setup for induction heating of Al-Alloy blank is also presented, together with a temperature distribution captured by a thermal image camera. Several recommendations on the deployment of induction heating for aluminium-sheets for hot stamping applications are given at the end of this paper.

\section{Numerical models of induction heating of aluminium sheets}

Induction heating of $\mathrm{Al}$-alloy blanks was studied using 3D simulations. The numerical studies involved simulating heating processes with different coil shapes and sizes, positioning, blank sizes, power parameters, as well as motion of the blanks. This section describes material properties and setups for the numerical models.

\subsection{Material properties}

In the simulations, the electrified copper coils with different shapes were used to heat up Al-alloy blanks in different sizes through induction heating. Although different dimensions of coils and blanks were simulated, material properties were kept consistent in all simulations. Table 1 gives the material properties of the workpiece and coil used in the simulations of induction heating. Thermal expansion, thermal conductivity and the mass density of aluminium alloy were considered as temperature-dependent properties and are listed in Table 2.

\subsection{Selection of induction coils}

The selection of the induction coils in this study involved selection of the cross-sectional shapes and arrangement of coils used for induction heating. 
Table 2. Temperature-dependent behaviour of Al-alloy.

\begin{tabular}{llllll}
\hline & \multicolumn{5}{c}{ Al-alloy sheet } \\
\hline Temperature $\left({ }^{\circ} \mathrm{C}\right)$ & $\begin{array}{l}\text { Thermal } \\
\text { expansion }\end{array}$ & $\begin{array}{l}\text { Temperature } \\
\left({ }^{\circ} \mathrm{C}\right)\end{array}$ & $\begin{array}{l}\text { Thermal conductivity } \\
(\mathrm{W} /(\mathrm{m} \cdot \mathrm{K}))\end{array}$ & $\begin{array}{l}\text { Temperature } \\
\left({ }^{\circ} \mathrm{C}\right)\end{array}$ & $\begin{array}{l}\text { Mass density } \\
\left(\mathrm{kg} / \mathrm{m}^{3}\right)\end{array}$ \\
\hline 20 & $2.18 \mathrm{e}-05$ & 50 & 280 & 20 & 2697.5 \\
200 & $2.18 \mathrm{e}-05$ & 100 & 220 & 300 & 2697.5 \\
250 & $2.21 \mathrm{e}-05$ & 150 & 200 & 350 & 2687.5 \\
300 & $2.26 \mathrm{e}-05$ & 200 & 200 & 400 & 2677.5 \\
350 & $2.32 \mathrm{e}-05$ & 250 & 200 & 450 & 2667.5 \\
400 & $2.37 \mathrm{e}-05$ & 300 & 200 & 500 & 2657.5 \\
450 & $2.42 \mathrm{e}-05$ & & 550 & 2647.5 \\
500 & $2.48 \mathrm{e}-05$ & & & 2637.5 \\
550 & $2.51 \mathrm{e}-05$ & & & \\
\hline
\end{tabular}

The cross-sectional shape of an induction coil is a very important factor affecting the heating performance. It needs to be considered carefully during the design of an induction heating process. Due to the electrical resistance of the coil material, heat is generated when high electric current is passing through the coil. If no cooling is deployed, the temperature in the coil will increase continuously. Circulated water cooling is usually adopted for transferring the generated heat away in order to reduce the temperature in the coil.

When an alternating current is applied on a cylindrical conductor, the highest current density is observed at the inner side of the conductor [23]. This phenomenon should be considered when choosing a suitable cross-sectional shape for the induction coil. For induction heating of a cylindrical surface, a cylindrical coil design can take the advantage of the phenomenon. While for induction heating of a metal sheet, a coil with rectangular cross-section can be placed more closely to the specimen and generate a more even eddy current and heating [23].

An induction coil with a hollow rectangular crosssection was chosen in this study for the induction heating of shaped aluminium-alloy blanks. As shown in Figure 1, the length $\mathrm{L}$, height $\mathrm{H}$ and wall thickness $\mathrm{T}$ are three keyparameters for the coil design. Cold water flows through the channel inside the coil for cooling. The size of the channel influences the flow rate of cooling water.

Wall thickness of the coil was chosen to be 1.2 times the effective skin-depth $\delta$. The effective skin-depth for the copper coil was $\delta=1.53$ and $\delta=0.78 \mathrm{~mm}$ respectively, when the applied power frequencies were 1800 and $7000 \mathrm{~Hz}$. The design wall thickness $\mathrm{T}$ was chosen as $2.0 \mathrm{~mm}$. Based on the requirement for heating power, design length $\mathrm{L}$ and height $\mathrm{H}$ were both chosen to be $8 \mathrm{~mm}$.

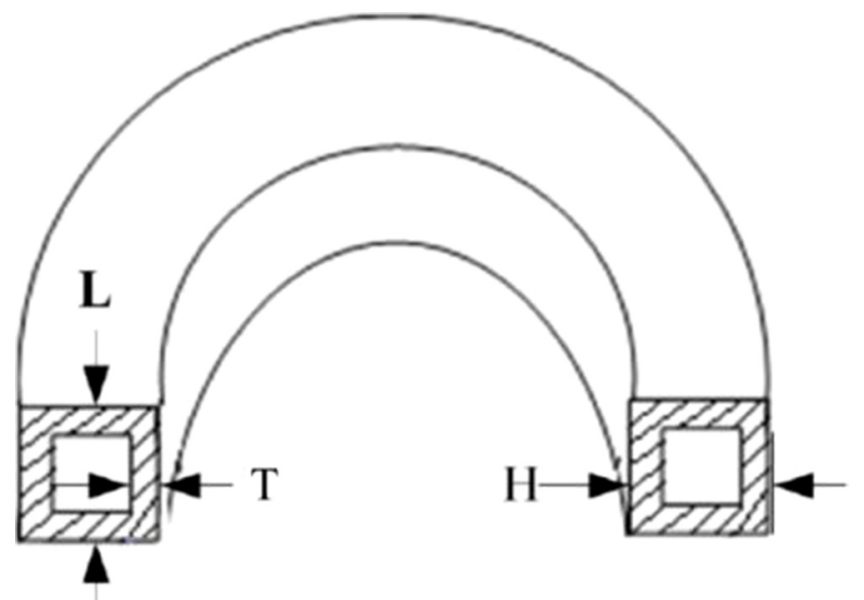

Fig. 1. Illustration of the cross-section of an induction coil.

Two different coil arrangements, namely longitudinal flux induction heating (LFH) and transverse flux induction heating (TFH), as shown in Figure 2, were considered for the induction heating of shaped Al-alloy sheets. Performance of these two coil arrangements was evaluated by using coupled electromagnetic-thermal simulations.

\subsection{Induction heating of aluminium blanks in different sizes and with different heating schemes}

The first set of numerical studies simulated the induction heating processes induced by a single induction coil. The effects of blank size and shape, coil arrangement and corner design, and also the blank movement, on the developed temperature profiles, were the main research focus. 

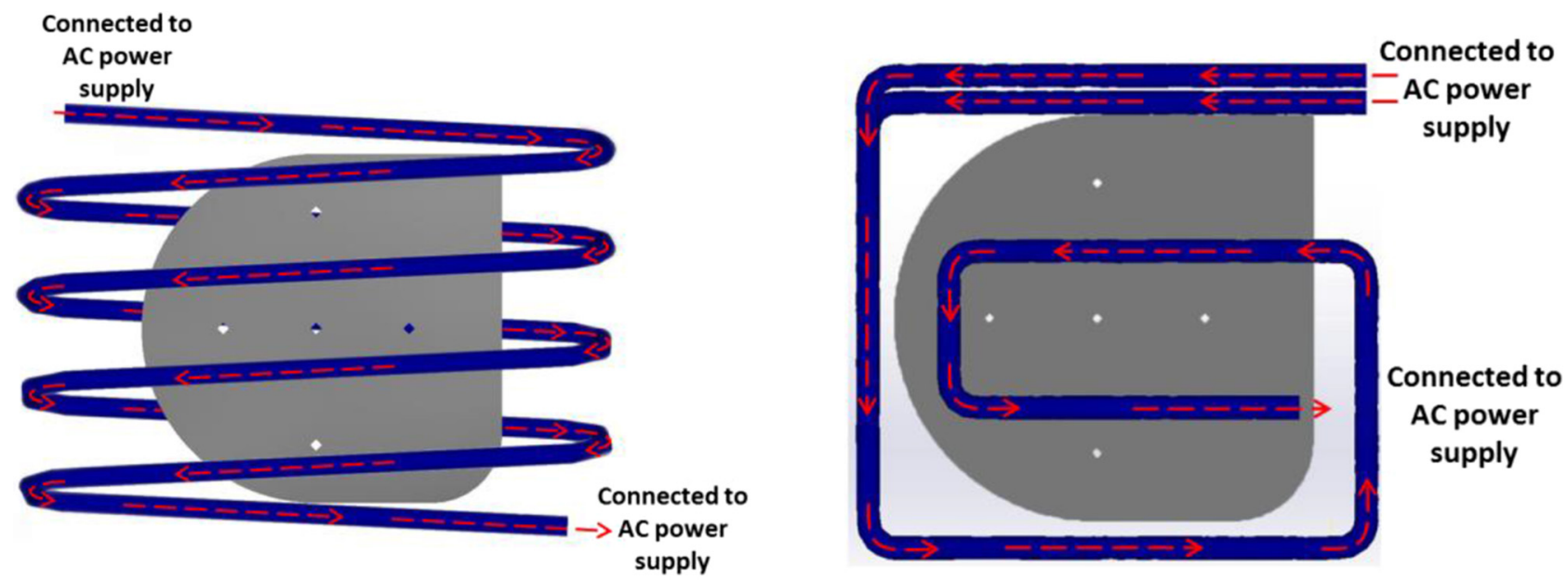

Fig. 2. Two types of coil arrangements for induction heating.

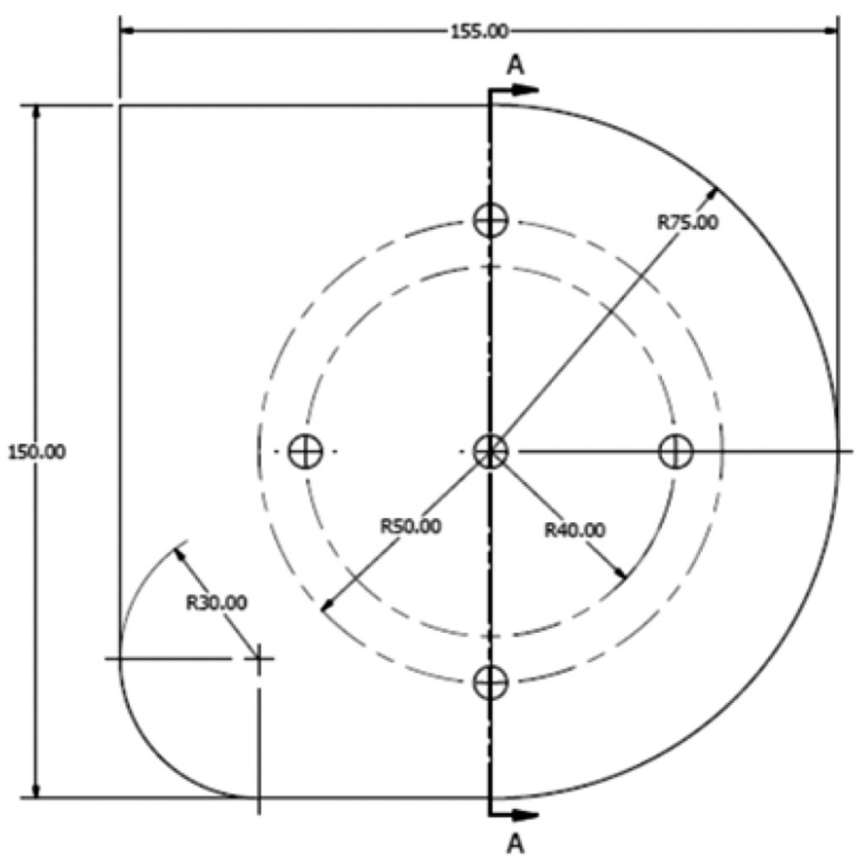

Fig. 3. Geometry of the small-sized Al-alloy blank used for analysis.

The inductive heating of shaped Al-alloy blanks was simulated by using both $\mathrm{LFH}$ and $\mathrm{TFH}$ induction coils. Figure 3 shows the dimensions of the shaped Al-alloy blank. The blank shape is not regular and it has 5 holes on it. These simulations can be used for evaluating the effects of coil arrangement and shape of blank on the temperature distributions generated by induction heating.

After that, induction heating of larger Al-alloy blanks of $400 \times 600 \times 2 \mathrm{~mm}$ was also studied numerically. In these simulations, a linear movement was applied to the blank while the induction coils were kept still. Coils with different corner shapes, namely rounded and right angled corners, were firstly simulated to investigate how the coil shapes can affect the temperature distribution. Figure 4 shows the geometry used for these simulations. After studying the shape effect of coils, an improved design of the induction coil was developed and the heating performance of this design was also evaluated. Figure 5 shows the geometry of an improved induction coil design. The 1st set of simulations was conducted with Finite Element (FE) software DEFORM. This software can be used to solve coupled electromagnetic - thermal problems.

The second set of simulations used a stationary blank and an arrangement of induction coils which covered the surface area of the workpiece for induction heating. This set of simulations mainly focuses on the effects of power settings. Parametric simulations of different power frequencies and current densities were conducted using FE software COMSOL Multiphysics. The AC/DC module of the software was used to study the induction heating process. Eddy currents and heat transfer were coupled in this model. The 3D model presented at Figure 6 illustrates the arrangement of coils and workpiece used for the parametric simulations. The workpiece was placed in the middle between the upper and lower coil sets. Table 3 lists the details of conducted simulations in this study.

\section{Numerical results}

This section presents the numerical results of simulations No. 1 to No. 7 listed in Table 3. The effects of different design and process parameters on the temperature profile developed on an inductively heated blank were studied by comparing the results from different coil arrangements, corner shapes, and different electrical settings.

\subsection{Induction heating of small Al-alloy blanks (Simulation No. 1 and No. 2)}

Figure 7 shows the temperature change on the shaped Alalloy in a transverse flux induction heating. It can be seen from the result that the maximum temperature on the blank induced by TFH induction heating increased very dramatically. Only in 7 seconds after the heating started, the maximum nodal temperature reached $525.0^{\circ} \mathrm{C}$. However, the developed temperature is highly uneven and a severe edge effect was observed. From the beginning of the heating 


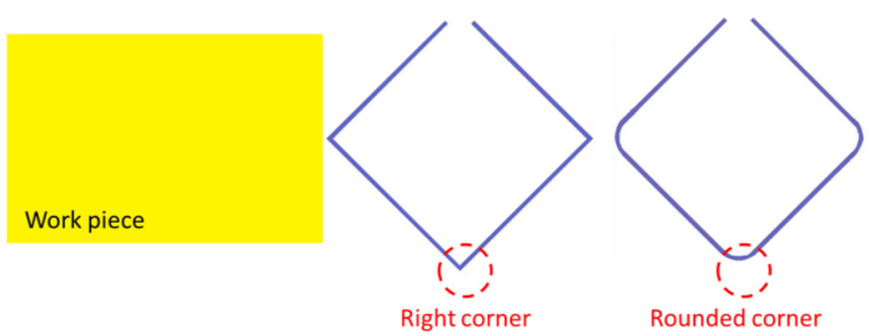

Fig. 4. A model of the induction heating with motion of the blank.
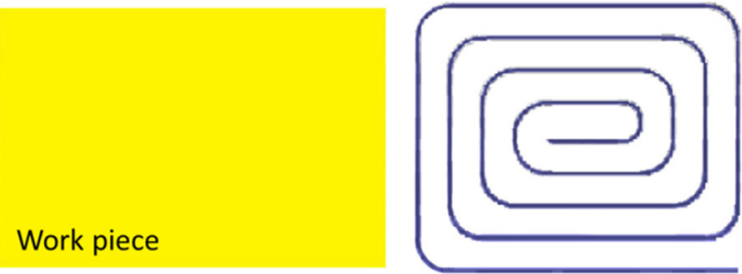

Fig. 5. Induction heating scheme with an alternative coil design.

process the temperature at the centre of the sheet was always lower than the temperature at the edge. Higher current density occurred near the edge of the workpiece. Temperature rises at the edge area was joule heating caused by the eddy current while the temperature increment at the sheet centre was created by weak induction heating and thermal conduction. Considering the coil design and the geometry of the workpiece, the edge effect occurred mainly because the coil stretched outside the workpiece and the eddy current concentrated at the edge of the material. Figure 8a plots the temperature history at different points on the workpiece in 7 seconds. The temperature difference induced by the edge effect increases with time and reaches as high as $470.0^{\circ} \mathrm{C}$ in 7 seconds.

A similar simulation process was applied to the longitudinal induction heating model and the final numerical result of the temperature distribution is plotted in Figure 8b. This result shows that within 27 seconds after the coil was electrified, part of the workpiece reached $525.0^{\circ} \mathrm{C}$. Without observing a severe edge effect, the temperature was distributed more evenly across the whole workpiece and the highest temperature occurs at the round corner. The greatest temperature difference in the workpiece is about $50.0^{\circ} \mathrm{C}$. Thus compared to the temperature profile generated by $\mathrm{TFH}$ induction heating, it appears that LFH heating can obtain higher temperature-distribution uniformity on the workpiece.

\subsection{Induction heating of large Al-alloy blanks with motion (Simulation No. 3, No. 4 and No. 5)}

Figure 9 shows the change of temperature in the Al-alloy sheet when it passed through the induction coil. The sheet was designed to move continuously but the simulation calculated the generated heat based on the relative position of coil and workpiece at each time step. However, the numerical results can still reveal uneven temperature distribution on the workpiece induced by the edge effect. An area with a relatively high temperature in the sheet had

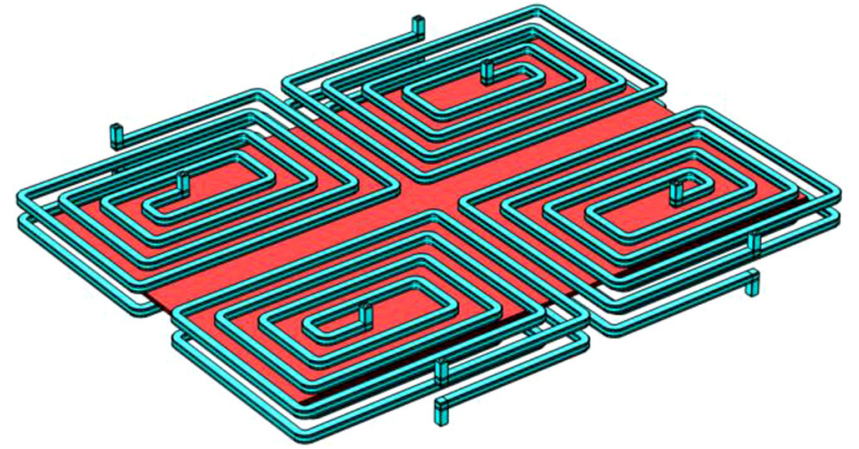

Fig. 6. A model of induction heating with four coils arrangement.

a similar shape to the coil and moved in a direction opposite to the movement of the sheet. The highest temperature was observed at the long edges, especially at each corner of the sheet. A high heating rate occurred in these areas due to the edge effect where the coil stretched outside the sheet and led to higher eddy current density. Temperatures at the centre of the sheet were generally lower. This area was merely heated up and cooled down very quickly after the coil passed through, leaving a very uneven temperature distribution on the workpiece.

Figure 10 presents the numerical results of induction heating which used a coil with rounded corners. Although the induction edge effect in the Al-alloy sheet could still be clearly observed, more of the area in the centre of the sheet was heated up by this coil design. A coil with rounded corners has the quality to produce a more even temperature distribution in the workpiece in an induction heating process.

After the study of cross-sections of the induction coils, corner design and edge effect, an alternative induction coil design was proposed. Figure 11 presents the results of the numerical study of this coil design. The results show that the proposed coil design has the potential to produce a more even temperature distribution pattern in the workpiece. Data reading from the simulation results also suggests that the temperature in the Al-sheet can increase by as high as $45.0^{\circ} \mathrm{C}$ in one second.

\subsection{Induction heating of large Al-alloy blanks with an array of coils (Simulation No. 6 and No. 7)}

The second set of simulations used a coil array for heating up an Al-alloy blank inductively. For the blank of $400.0 \times 600.0 \times 2.0 \mathrm{~mm}$, a total of 8 induction coils were 
Table 3. List of details of the conducted simulations.

\begin{tabular}{|c|c|c|c|c|c|}
\hline No. & Blank size & Coil feature & Current density $\left(\mathrm{A} / \mathrm{mm}^{2}\right)$ & Current frequency $(\mathrm{Hz})$ & Blank motion $(\mathrm{mm} / \mathrm{s})$ \\
\hline 1 & Small & Trans-verse (LFH) & 54 & 5000 & $\mathrm{~N} / \mathrm{A}$ \\
\hline 2 & Small & Longitu-dinal (TFH) & 54 & 5000 & $\mathrm{~N} / \mathrm{A}$ \\
\hline 3 & Large & TFH, right corner & 14 & 2000 & 50 \\
\hline 4 & Large & $\mathrm{TFH}$, rounded corner & 14 & 2000 & 50 \\
\hline 5 & Large & $\mathrm{TFH}$, rounded corner & 14 & 2000 & 50 \\
\hline 6 & Large & $\mathrm{TFH}$, rounded corner & 27 & $5000,10000,15000$ & $\mathrm{~N} / \mathrm{A}$ \\
\hline 7 & Large & $\begin{array}{l}\mathrm{TFH}, \\
\text { rounded corner }\end{array}$ & $9,12,15,18,21,24,27,30$ & 5000 & $\mathrm{~N} / \mathrm{A}$ \\
\hline
\end{tabular}

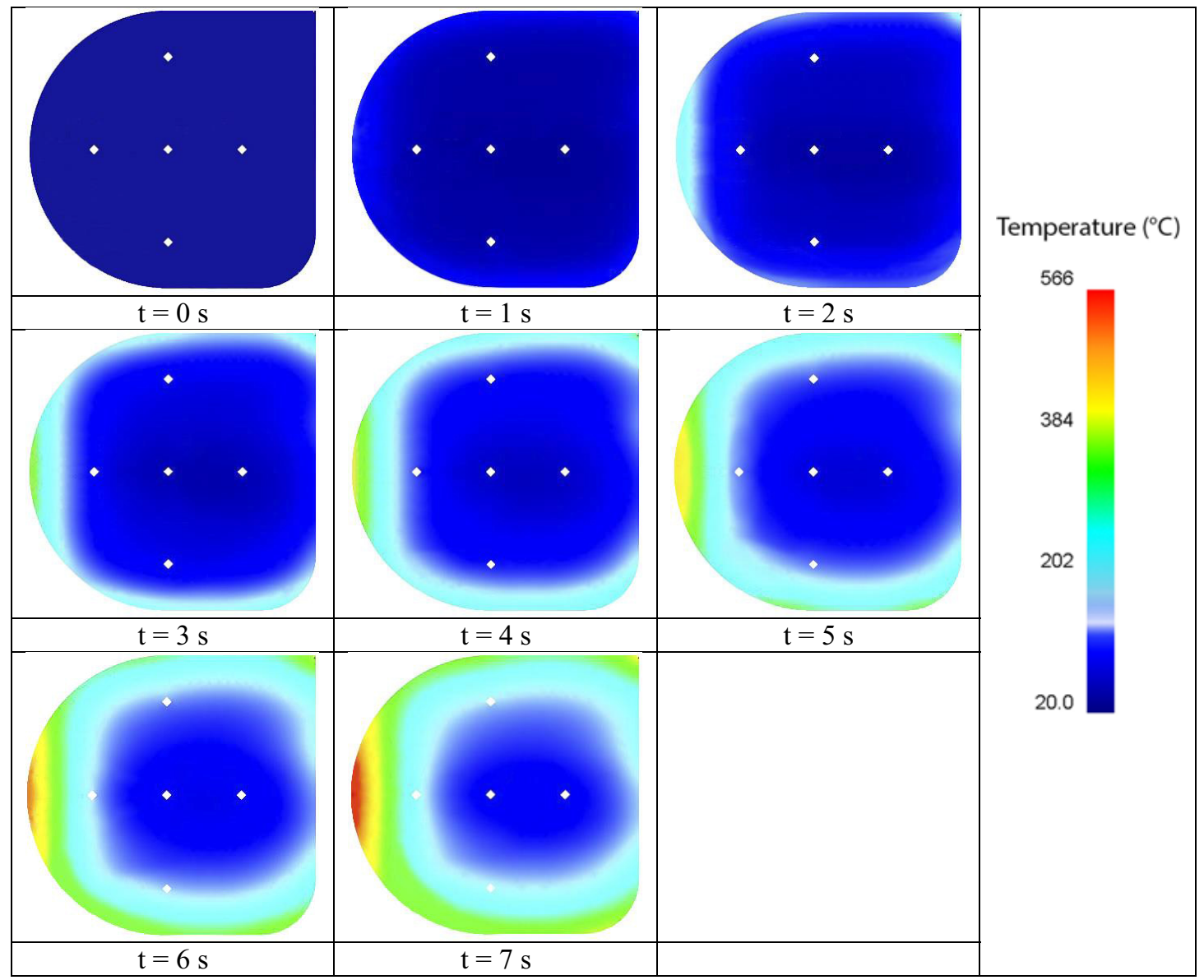

Fig. 7. Temperature development using transverse flux induction heating (Simulation No. 1).

used. Twelve simulations were done with different settings of alternating frequencies and current densities. Figure 12 shows streamlines of magnetic flux density.

In order to study the effect of alternating current frequencies on the temperature development of induction heating, the induction coils were energized by alternating currents of the frequency of 5000,10000 and $15000 \mathrm{~Hz}$. Temperature distributions on the workpiece were plotted and shown in Figure 13.

From the results of different current frequencies, an edge effect can be clearly observed. All these simulations were conducted using the current density of $27.0 \mathrm{~A} / \mathrm{mm}^{2}$. As the frequency of the power supply increased, the edge effect became more obvious. For all the simulations, the edges of the workpiece were firstly heated up while the centre of the blank was still relatively cool. At $40 \mathrm{~s}$ after the heating process started, the hottest part of the blank had a temperature above $525.0^{\circ} \mathrm{C}$ but the coolest part was still below $150.0^{\circ} \mathrm{C}$. Figure 14 shows the development of highest and lowest temperatures on the workpiece at different current frequencies. The highest temperature on the blank is severely affected by the supply frequency, while all the blanks obtain similar lower temperatures. The temperature difference in the workpieces increases with increasing current frequency. 

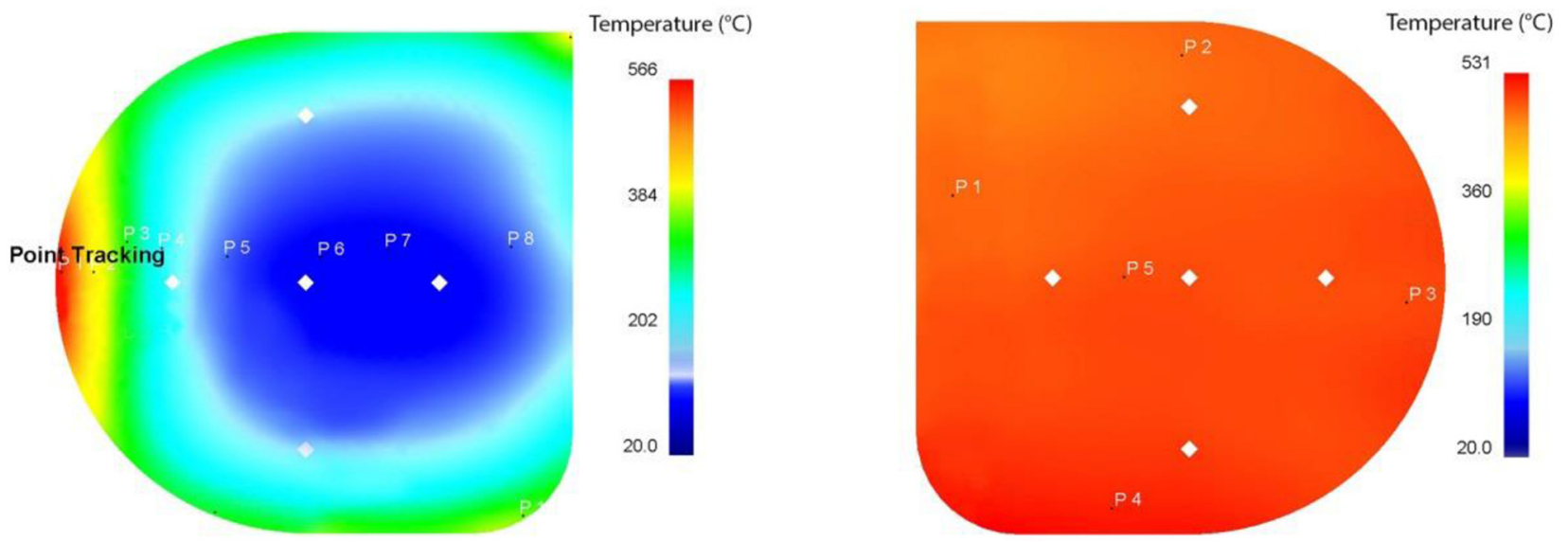

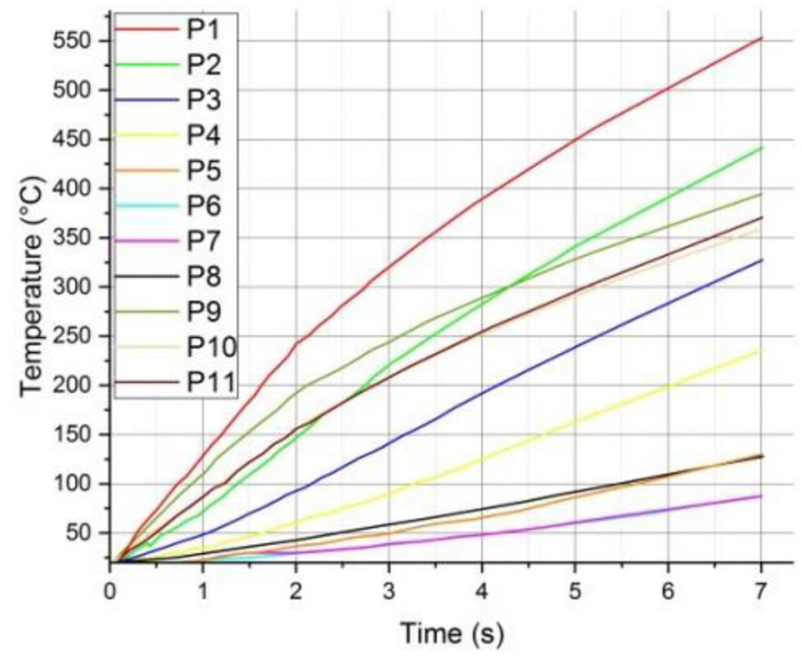

(a)

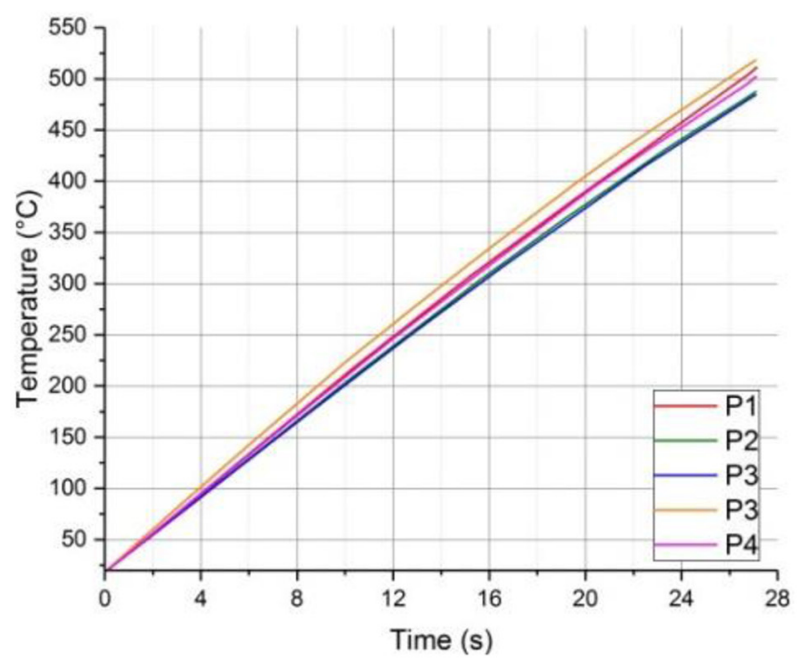

(b)

Fig. 8. Comparison of temperatures for induction heating with TFH method and LFH method. (a) Temperature profiles for transverse flux induction heating in 7 seconds (Simulation No. 1); (b) temperature profiles for longitudinal flux induction heating in 27 seconds (Simulation No. 2).

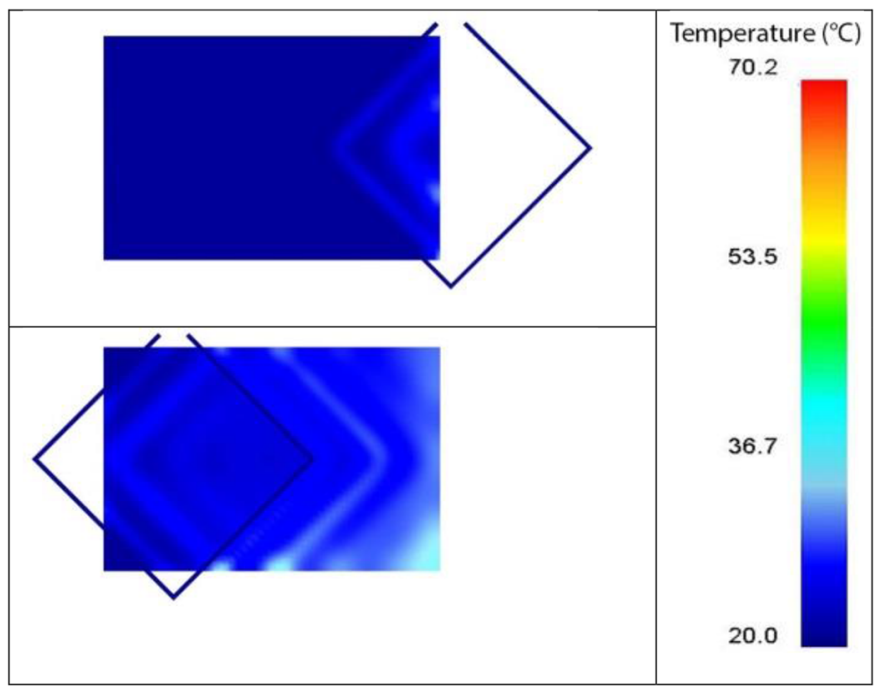

Fig. 9. Numerical result of the inductive heating process with coil with right angled corner (Simulation No. 3).

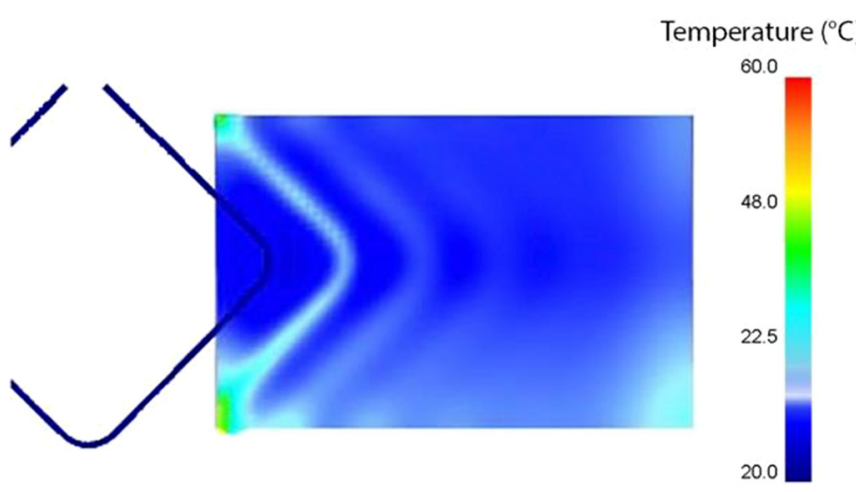

Fig. 10. Temperature distribution of the inductive heating process with coil with rounded corners (Simulation No.4).

Similar numerical studies were conducted to study the effect of current density on the induction heating process. This time, the current frequencies were kept the same at $5000 \mathrm{~Hz}$, while the current density changed from 9 to 


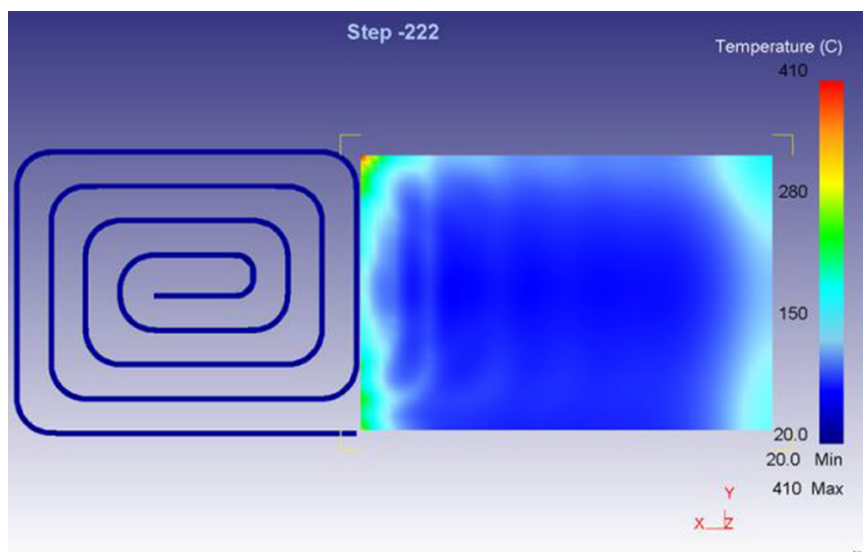

Fig. 11. Simulation result of the induction heating with optimised induction coil design (Simulation No. 5).

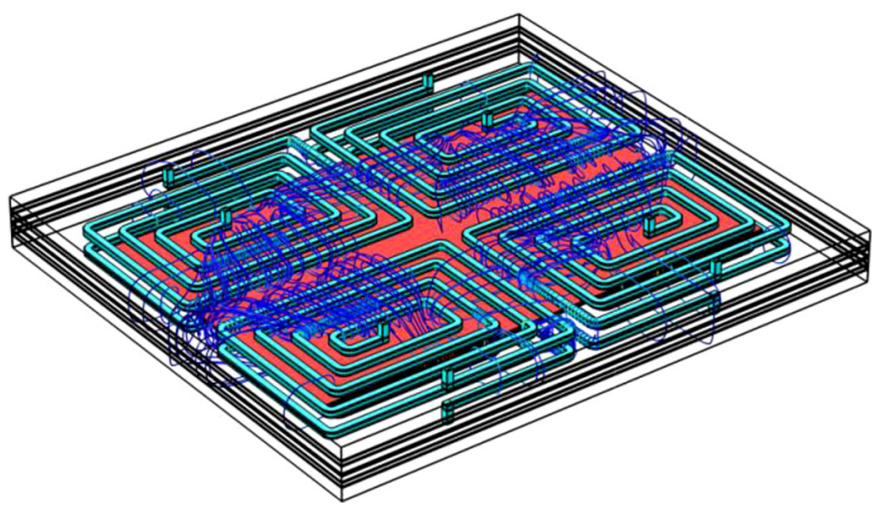

Fig. 12. Magnetic flux density for induction heating simulated.

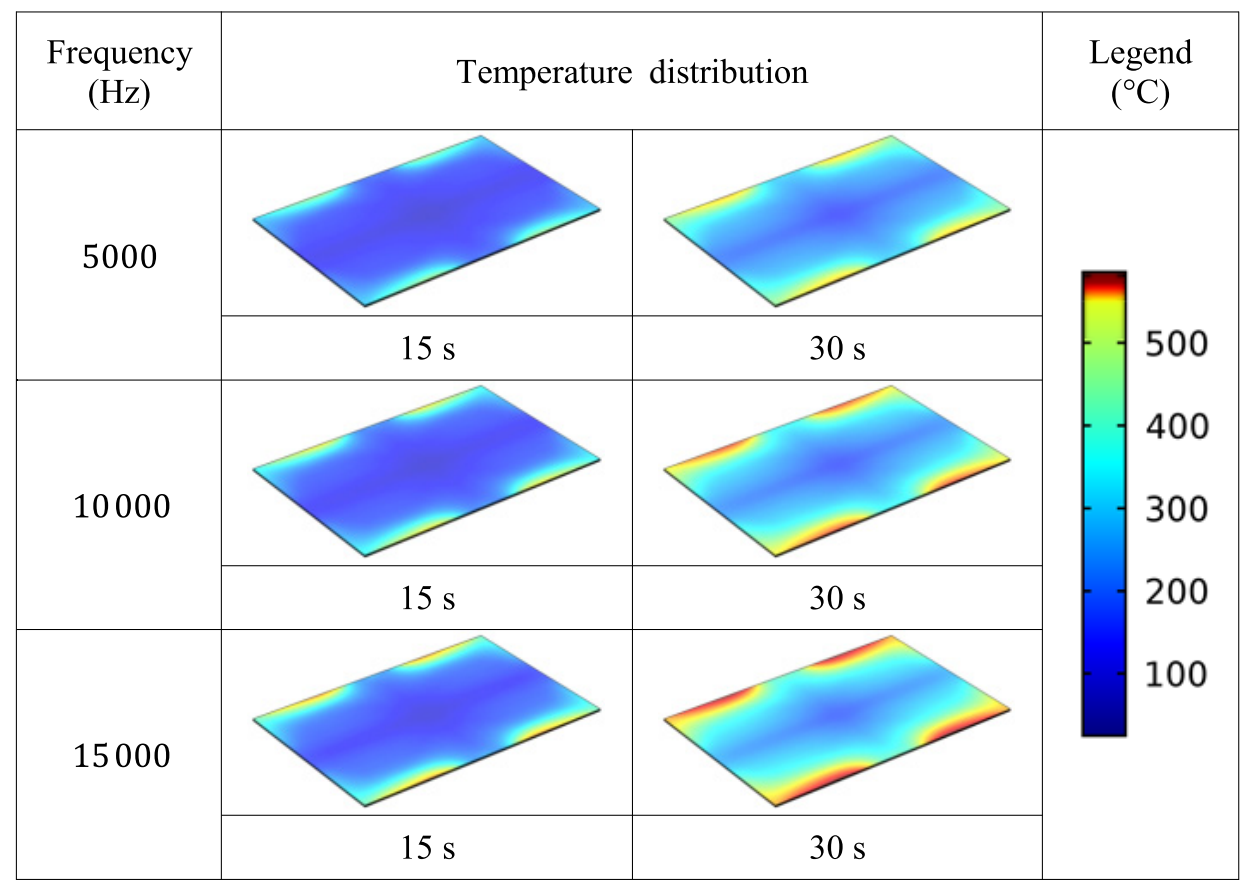

Fig. 13. Temperature distribution in the workpiece at different current frequencies.

$30 \mathrm{~A} / \mathrm{mm}^{2}$. A similar inhomogeneous distribution of temperature was also observed in these simulations. Figure 15 shows the highest and lowest temperatures developed on the Al-alloy sheet. Although the highest temperature and the temperature difference on the blank increased as the current for induction heating increased, the lowest temperature on the workpiece was affected more strongly by the current densities than the frequencies. In this case, the results suggest that for an optimised induction heating process, it is favourable to use an induction current of high density which increases the heating rate for the edges and the centre. Also at the same time, to use a low frequency which significantly reduces the edge effect without affecting the centre of the workpiece too much.

\section{Initial experiments of induction heating of aluminium sheets}

After various numerical studies were done for induction heating, an initial physical test was conducted to study the temperature distribution on a shaped Al-alloy blank generated by LFH induction heating. The experimental setup and initial test results obtained by the thermal imaging camera are presented in this section.

\subsection{Setup for the induction heating experiment}

In order to evaluate the feasibility of using induction heating for hot stamping, initial experiments were set up. 

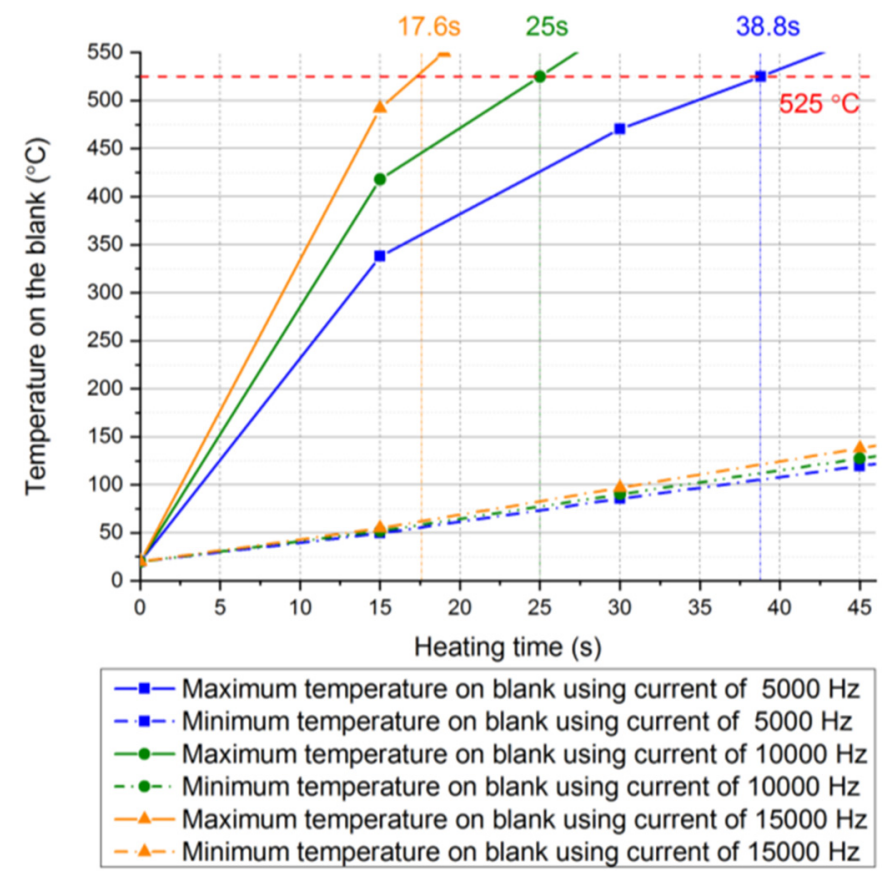

Fig. 14. Highest and lowest temperature in the workpiece heated by the current at different frequencies.

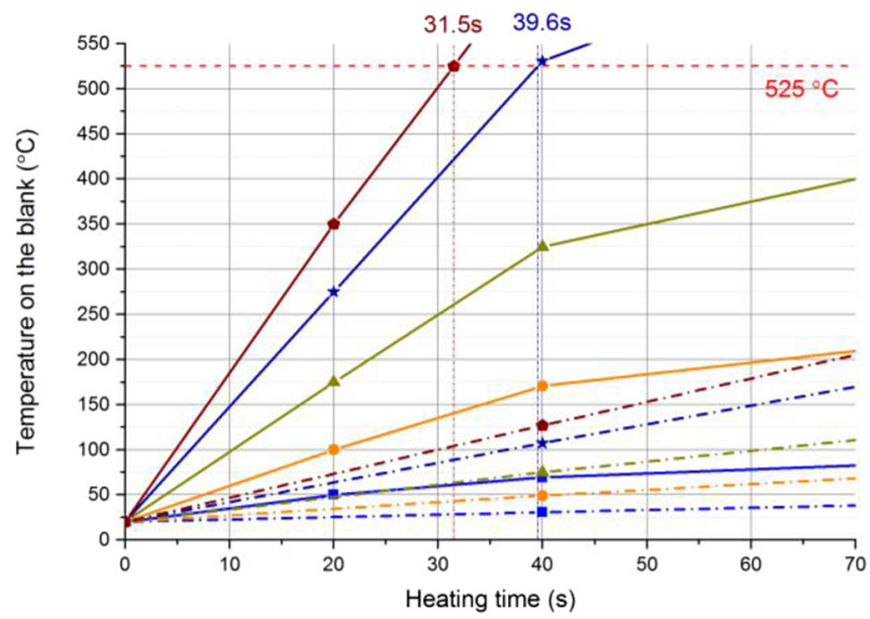

- Maximum temperature on blank with current density of $9 \mathrm{~A} / \mathrm{mm}^{\wedge} 2$
- Minimum temperature on blank with current density of $9 \mathrm{~A} / \mathrm{mm}^{\wedge} 2$
- Minimum temperature on blank with current density of $15 \mathrm{~A} / \mathrm{mm}^{\wedge} 2$
- Maximum temperature on blank with current density of $15 \mathrm{~A} / \mathrm{mm}^{\wedge} 2$
- Maximum temperature on blank with current density of $21 \mathrm{~A} / \mathrm{mm}^{\wedge} 2$
- Minimum temperature on blank with current density of $27 \mathrm{~A} / \mathrm{mm}^{\wedge} 2$
-

Fig. 15. Highest and lowest temperature in the workpiece at different current densities.

An Al-alloy blank sheet having the dimensions as shown in Figure 3 was made and used for the induction heating (Fig. 16). The blank had a thickness of $2 \mathrm{~mm}$. A coil design based on the LFH heating method was used because LFH is a widely used induction heating technology and the setup

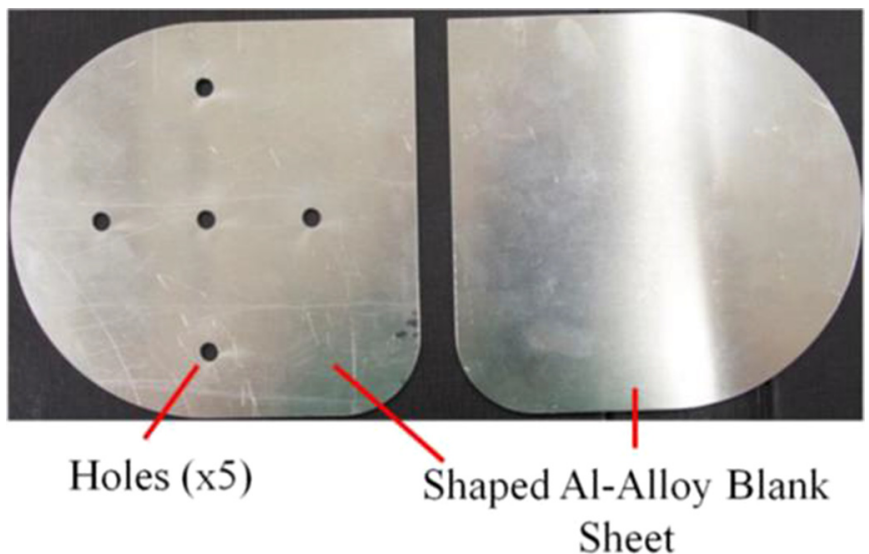

Fig. 16. Al-alloy blanks used for the initial experiment of induction heating.

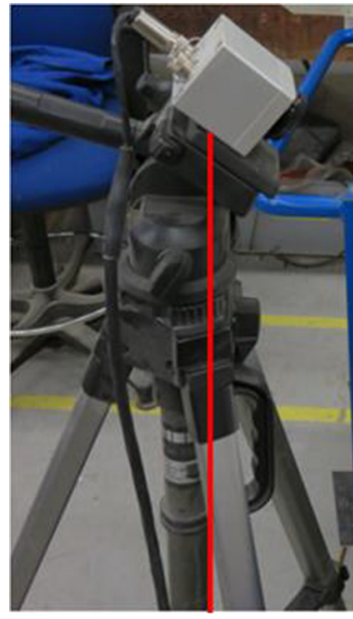

Thermal Image Camera

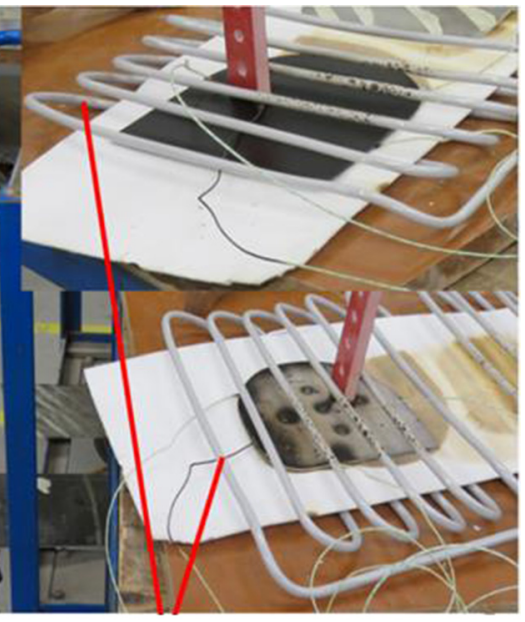

LFH Induction

Coil
Fig. 17. Experimental setup for the induction heating of $\mathrm{Al}-$ Alloy blanks.

for this heating method is relatively simple. Figure 17 shows the experimental setup. The induction coil was energised by an alternating current of $133 \mathrm{kHz}$ with a power of $16.4 \mathrm{~kW}$. A thermal imaging camera (infrared camera) was used to monitor the temperature distribution. This system can measure the temperature distribution with a resolution of $640 \times 480$ or $382 \times 288$ pixels.

\subsection{Temperature distributions in Al-alloy blanks}

Figure 18 shows the temperature distribution in an Al-Alloy blank heated up with the LFH induction heating method. This heating experiment was only for initial validation purpose and therefore, the blank was only heated up to, approximately, $200^{\circ} \mathrm{C}$. Using the lower temperature was also due to the restriction of the experimental environment available. The temperature distribution uniformity and heating rate were the two main interests of the experiment 


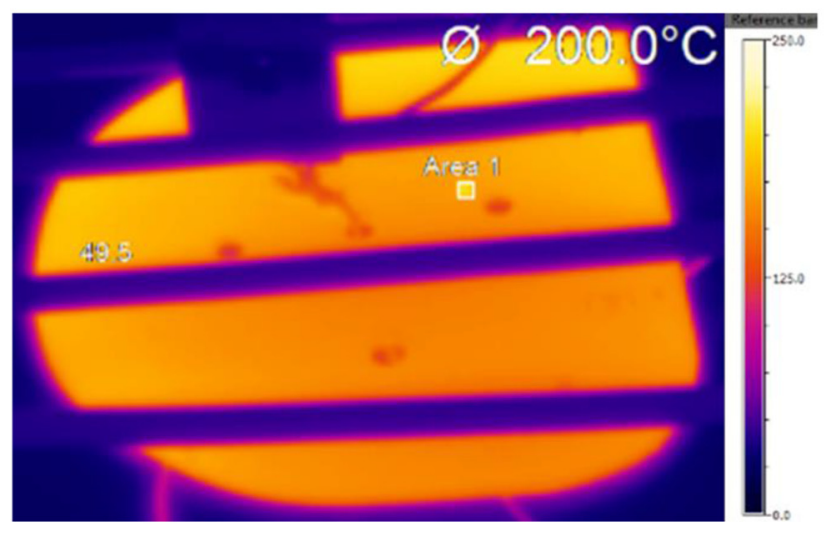

(a)

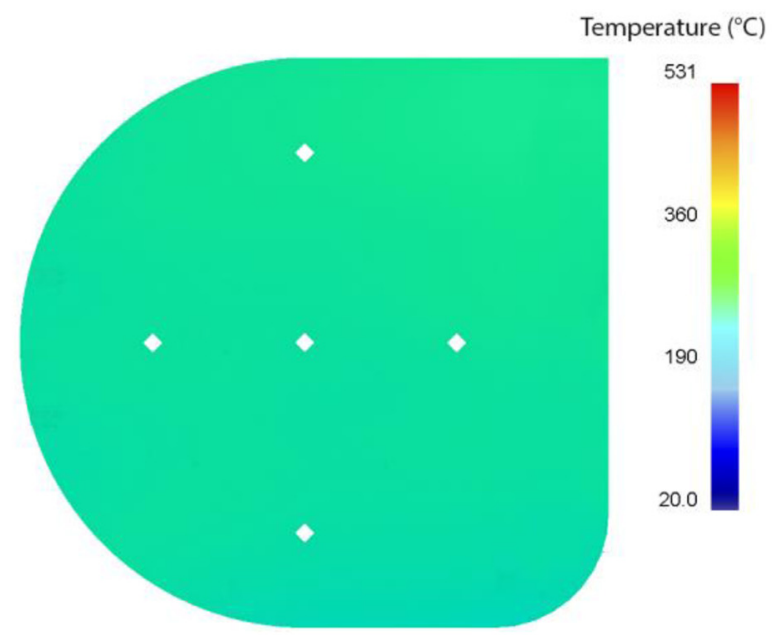

(b)

Fig. 18. Temperature distribution captured by a thermal image camera (a) and predicted temperatures using FEM for a simialr condition (b).

since these would be main concerns, regarding if this heating method could be used for heating Al-Alloy blanks for hot stamping applications: one concerns heating quality while another concerns the productivity.

As shown in Figure 18a, by using the LFH method, the temperature distribution on the heated blank was quite even. Comparing the measured result to the predicted temperature shown in Figure 18b, similarities can be found regarding the temperature difference and distribution in the blank. The maximum temperature predicted in the simulation at this stage of heating was approximately slightly higher than $200^{\circ} \mathrm{C}$. For both the experimental and numerical results, the highest temperatures were observed along the right-angle corner edge of the blank, while lowest temperatures appeared at the centre of the blank as well as at the rounded-corner.

\section{Conclusions}

This study examined heating schemes and process parameters in induction heating of aluminium blanks for hot stamping applications. Numerical simulations were conducted to investigate the effects of coil designs and power parameters on the induction heating process for Alalloy blanks. Aspects like coil design selection, edge effect in induction heating, corner shape of the coil, blank movement, and current properties, etc. were considered and studied. The main conclusions from this study are as follows:

- both TFH and LFH induction heating process were studied numerically. The TFH heating process can achieve high heating rates due to the induction edge effect. The edge effect also causes the metal sheet to be heated up unevenly. The LFH heating method can reduce the edge effect. However, this method is only practically feasible for small blanks;

- coils with sharp corners and rounded corners were both used for the induction heating studies of a moving blank. The numerical results show that the coil with rounded corners is likely to result in more uniform heating;
- an alternative coil design was proposed for the heating of large Al-alloy sheets and a numerical simulation showed its potential to produce quick and relatively more uniform heating;

- induction heating with coil arrays was also studied. Parametric simulations were conducted for different supplied current frequencies. The results suggest that to obtain relatively even temperature distributions on aluminium sheets with thicknesses of $2 \mathrm{~mm}$, currents with low alternating frequency is more applicable;

- initial experiments were set up and conducted for the induction heating of small Al-alloy blanks of non-regular shape. Resulting temperature distributions were captured by using a thermal imaging camera. It was shown that by using an LFH method, a temperature distribution of high uniformity can be obtained, this was also observed in the numerical study.

To adopt induction heating of aluminium blanks in hot stamping production in practice, special attention should be paid to the selection of the coil design, heating method, blank geometry, blank movement, and power control. Only with optimal combinations of these factors should the aluminium blanks be heated at the desired rate to acceptable temperatures and distributions in order to achieve high-quality hot stampings.

In the future, more physical experiments and in-depth studies of heating rate and temperature distribution will be conducted with different coil designs and power settings. The numerical modelling will be validated thoroughly, using more experimental results. All of these should result in improved heating process designs and increased hot-stamping process efficiency for hot-forming of aluminium sheets.

\section{References}

1. E. Kilinç, D. Kaya, F.Ç. Kiliç, M. Eyidoğan, M. Özkaymak, O. Taylan, W. Pedrycz, An energy efficiency analysis of an industrial reheating furnace and an implementation of efficiency enhancements methods, Energy Explor. Exploit. 32 (2015) 989-1003 
2. W. Liang, Y. Liu, B. Zhu, M. Zhou, Y. Zhang, Conduction heating of boron alloyed steel in application for hot stamping, Int. J. Precis. Eng. Manuf. 16 (2015) 1983-1992

3. W.K. Liang, L. Wang, Y. Liu, Y.L. Wang, Y.S. Zhang, Blank shape sensitivity on temperature distribution of hot stamping boron steel through conduction heating, Adv. Mater. Res. 1063 (2014) 211-214

4. K. Mori, S. Maki, Y. Tanaka, Warm and hot stamping of ultra high tensile strength steel sheets using resistance heating, CIRP Ann. - Manuf. Technol. 54 (2005) 209-212

5. L. Jakubovičová, G. Andrej, K. Peter, S. Milan, Optimization of the induction heating process in order to achieve uniform surface temperature, Procedia Eng. 136 (2016) 125-131

6. S. Klonk, PhD thesis, Ecole Nationale Supérieure des Mines de Paris, 2013

7. M.W. Kennedy, S. Akhtar, J.A. Bakken, R.E. Aune, in: S.N. Monteiro, D.E. Verhulst, P.N. Anyalebechi, J.A. Pomykala (Eds.), Proceedings of the EPD Congress 2011, San Diego, 2011, pp. 707-722

8. B.J. Yang, A. Hattiangadi, W.Z. Li, G.F. Zhou, T.E. McGreevy, Simulation of steel microstructure evolution during induction heating, Mater. Sci. Eng. A 527 (2010) 2978-2984

9. A. Bermúdez, D. Gómez, M.C. Muñiz, P. Salgado, Transient numerical simulation of a thermoelectrical problem in cylindrical induction heating furnaces, Adv. Comput. Math. 26 (2007) 39-62

10. D. Istardi, A. Triwinarko, Induction heating process design using COMSOL ${ }^{\circledR}$ multiphysics software, TELKOMNIKA (Telecommunication Comput. Electron. Control) 9 (2015) 327

11. H.K. Jung, C.G. Kang, Induction heating process of an Al-Si aluminum alloy for semi-solid die casting and its resulting microstructure, J. Mater. Process. Technol. 120 (2002) $355-364$
12. N. Kesangam, S. Pinitsoontorn, S. Srimanosaowapak, Science Direct Effect of initial microstructure on induction heating of A319 aluminium alloy, Mater. Today Proc. 5 (2018) 9615-9623

13. F. Shang, E. Sekiya, Y. Nakayama, Application of highfrequency induction heating apparatus to heat treatment of 6061 aluminum alloy, Mater. Trans. 52 (2011) 2052-2060

14. N. Barman, J. Mukherjee, P. Dutta, Numerical simulation of induction heating of aluminum alloy billets, Solid State Phenom. 141-143 (2009) 133-138

15. R. Goldstein, Design and fabrication of inductors for heat treating, brazing, and soldering, Induction Heat. Heat Treat. 4 (2018) 619-632

16. M.H. Tavakoli, H. Karbaschi, F. Samavat, Computational Modeling of Induction Heating Process, Prog. Electromagn. Res. Lett. 11 (2009) 93-102

17. M.W. Kennedy, Licentiate thesis, Royal Institute of Technology, Stockholm, 2013

18. L. Larsson, Licentiate thesis, Lund University, Lund, 2005

19. I. Doležel, P. Kropík, B. Ulrych, Induction heating of thin metal plates in time-varying external magnetic field solved as nonlinear hard-coupled problem, Appl. Math. Comput. 219 (2013) 7159-7169

20. J. Sun, S. Li, C. Qiu, Y. Peng, Numerical and experimental investigation of induction heating process of heavy cylinder, Appl. Therm. Eng. 134 (2018) 341-352

21. X. Fu, B. Wang, X. Tang, H. Ji, X. Zhu, Study on induction heating of workpiece before gear rolling process with different coil structures, Appl. Therm. Eng. 114 (2017) 1-9

22. M. Kranjc, A. Zupanic, D. Miklavcic, T. Jarm, Numerical analysis and thermographic investigation of induction heating, Int. J. Heat Mass Transf. 53 (2010) 3585-3591

23. S. Zinn, S.L. Semiatin, E.P.R. Institute, and B.M.I.C. Laboratories, Elements of induction heating: Design, control, and applications, ASM International, 1988

Cite this article as: Yankang Tian, Libo Wang, Gerald Anyasodor, Zhenhai Xu, Yi Qin, Heating schemes and process parameters of induction heating of aluminium sheets for hot stamping, Manufacturing Rev. 6, 17 (2019) 